Supporting Information

\title{
Direct Growth of Substrate-Adhered Graphene on Flexible Polymer Substrates for Soft Electronics
}

Eunho Lee ${ }^{1}$, Seung Goo Lee ${ }^{2}$, and Kilwon Cho ${ }^{1 *}$

${ }^{1}$ Department of Chemical Engineering and Center for Advanced Soft Electronics, Pohang University of Science and Technology (POSTECH), Pohang 37673, Korea

${ }^{2}$ Department of Chemistry, University of Ulsan, Ulsan 44610, Korea

*E-mail: kwcho@postech.ac.kr 


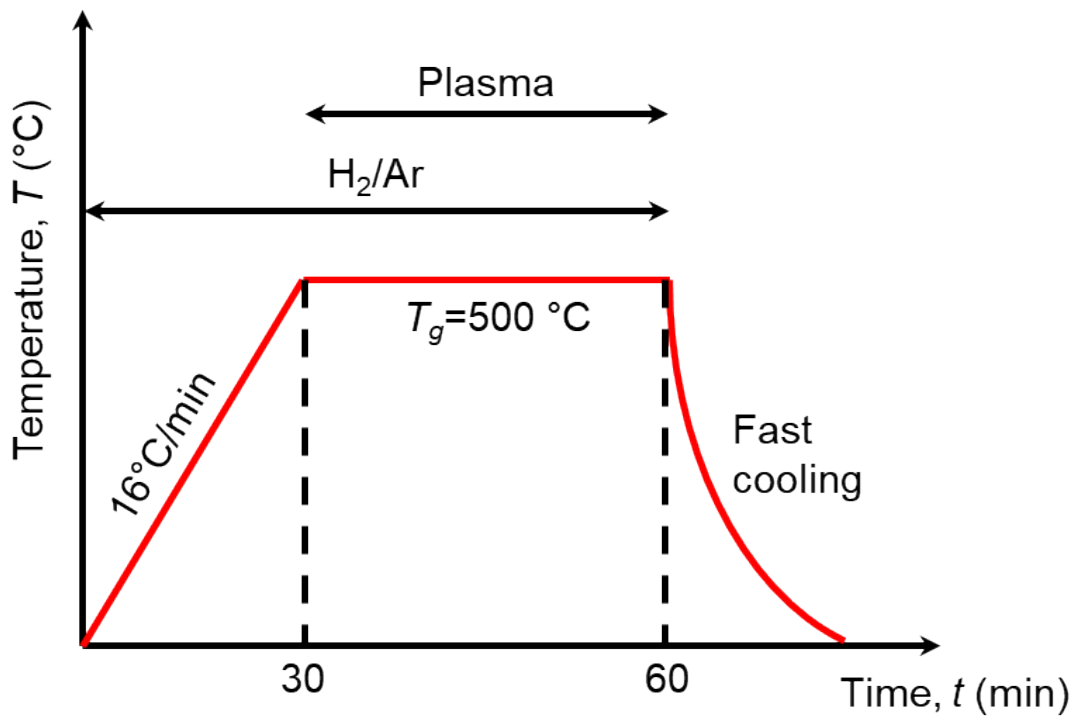

Figure S1. Temperature profile of graphene growth condition. The growth temperature is set at $500{ }^{\circ} \mathrm{C}$ under plasma-enhanced process. 

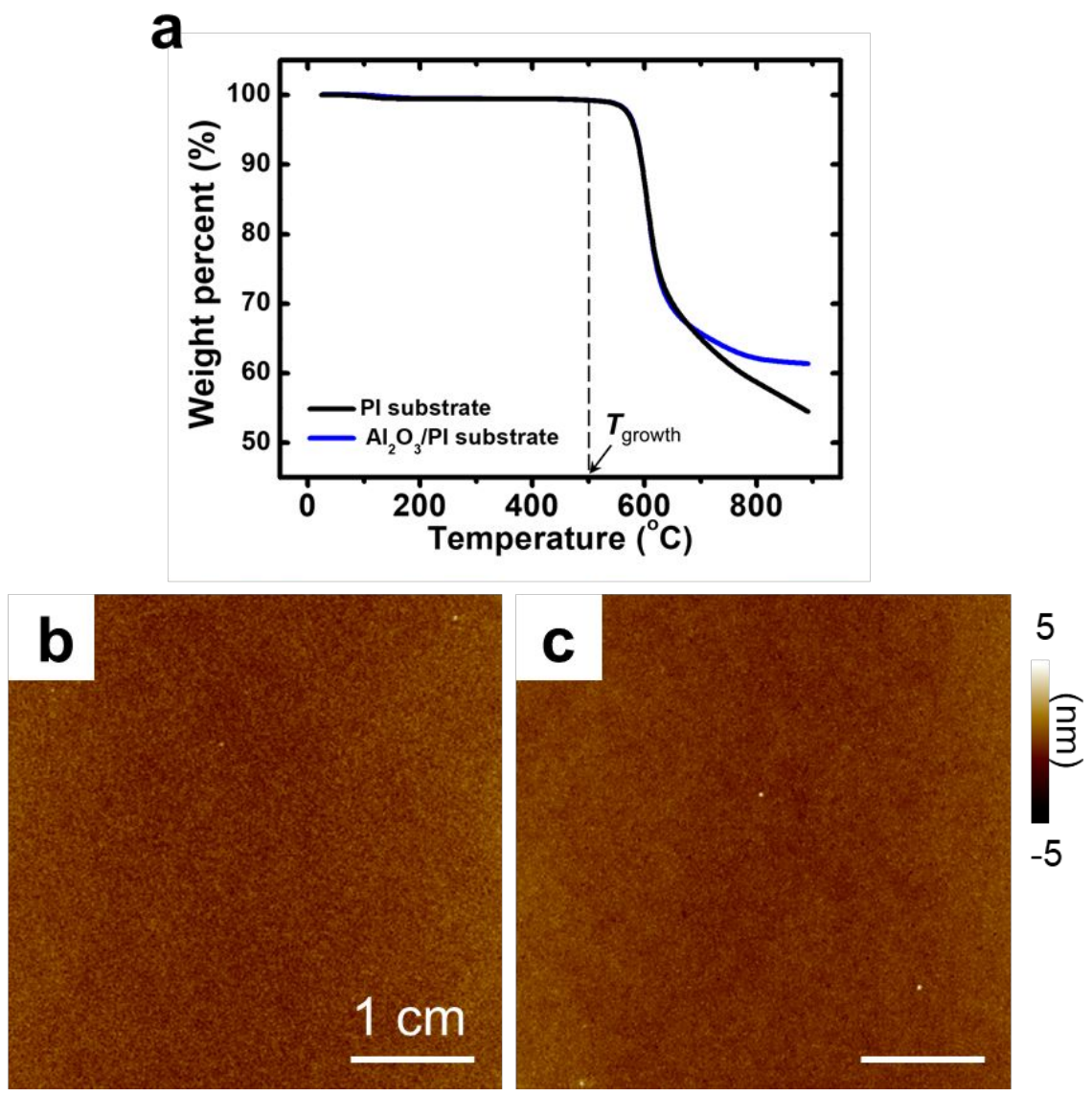

Figure S2. (a) Thermal characteristics of $\mathrm{PI}$ and $\mathrm{Al}_{2} \mathrm{O}_{3} / \mathrm{PI}$ substrate under $\mathrm{N}_{2}$ atmosphere. AFM morphology of (b) PI substrate and (c) $\mathrm{Al}_{2} \mathrm{O}_{3} / \mathrm{PI}$ substrate. 

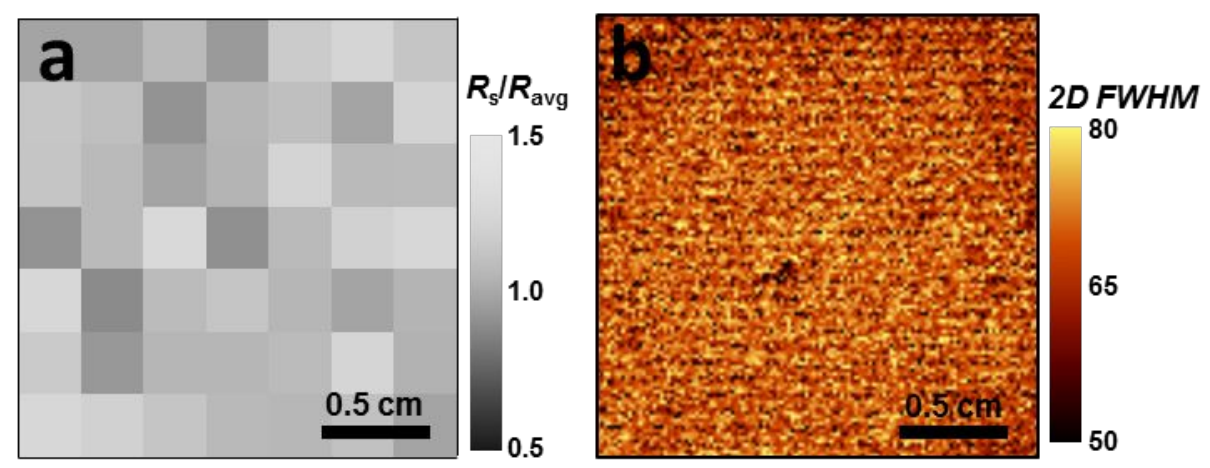

Figure S3. (a) The mapping images of the electrical sheet resistance and 2D FWHM of the synthesized graphene. 


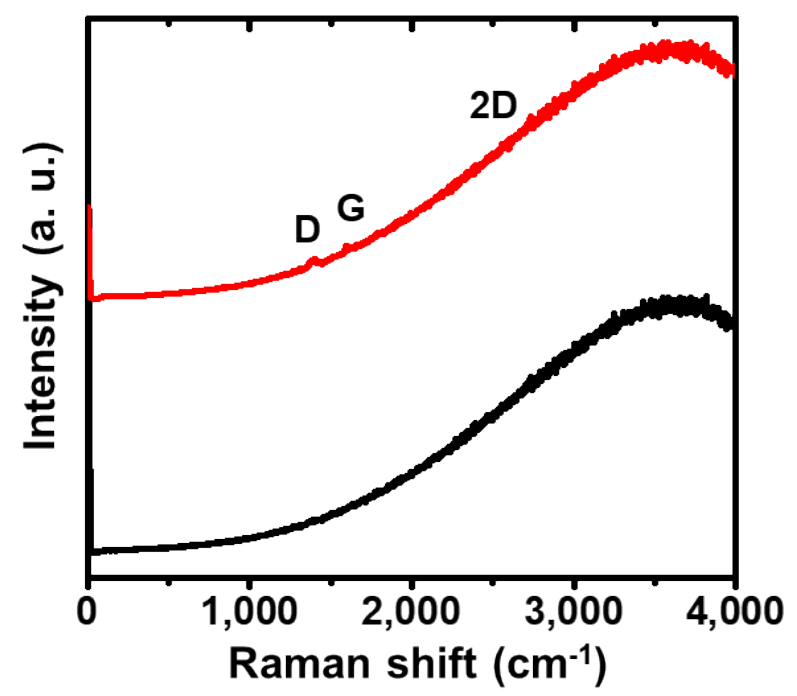

Figure S4. Single Raman spectrum of synthesized graphene on the bare PI (black) and the $\mathrm{Al}_{2} \mathrm{O}_{3} / \mathrm{PI}$ substrate (red). 


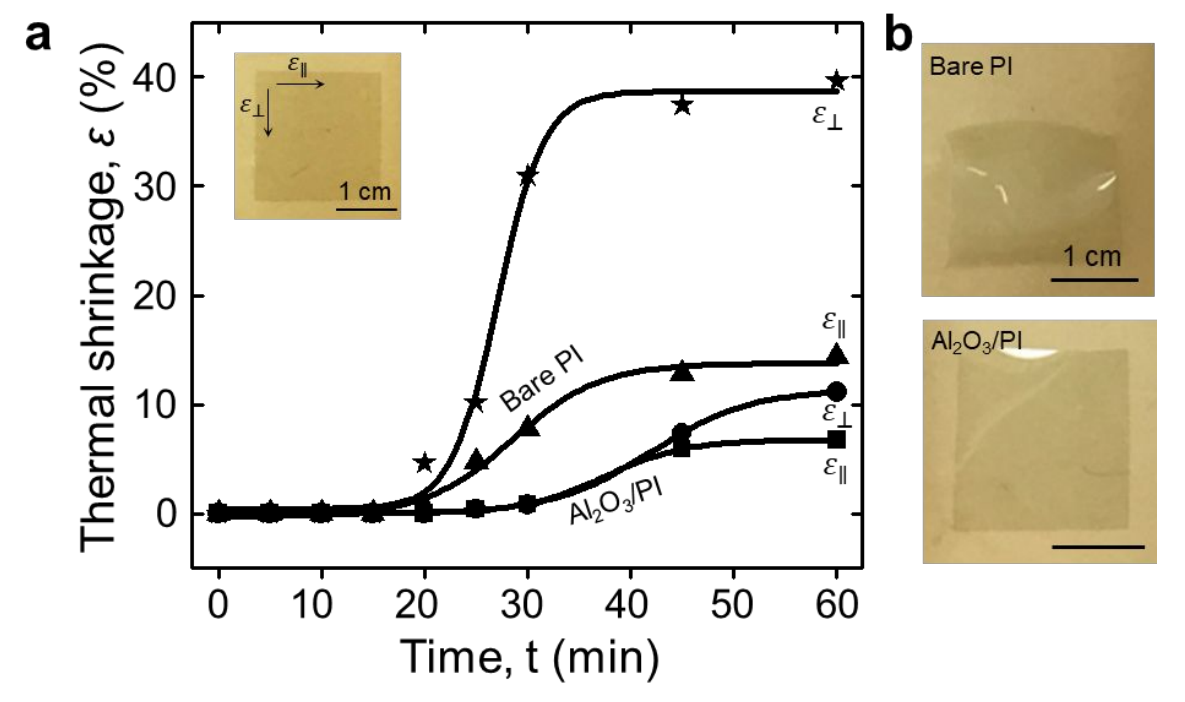

Figure S5. (a) Thermal shrinkage profiles of bare PI and $\mathrm{Al}_{2} \mathrm{O}_{3} / \mathrm{PI}$ substrates as a function of heating time at $500{ }^{\circ} \mathrm{C}$. (b) Optical images of thermal shirked bare PI substrate (top) and Al2O3/PI substrate (bottom). 

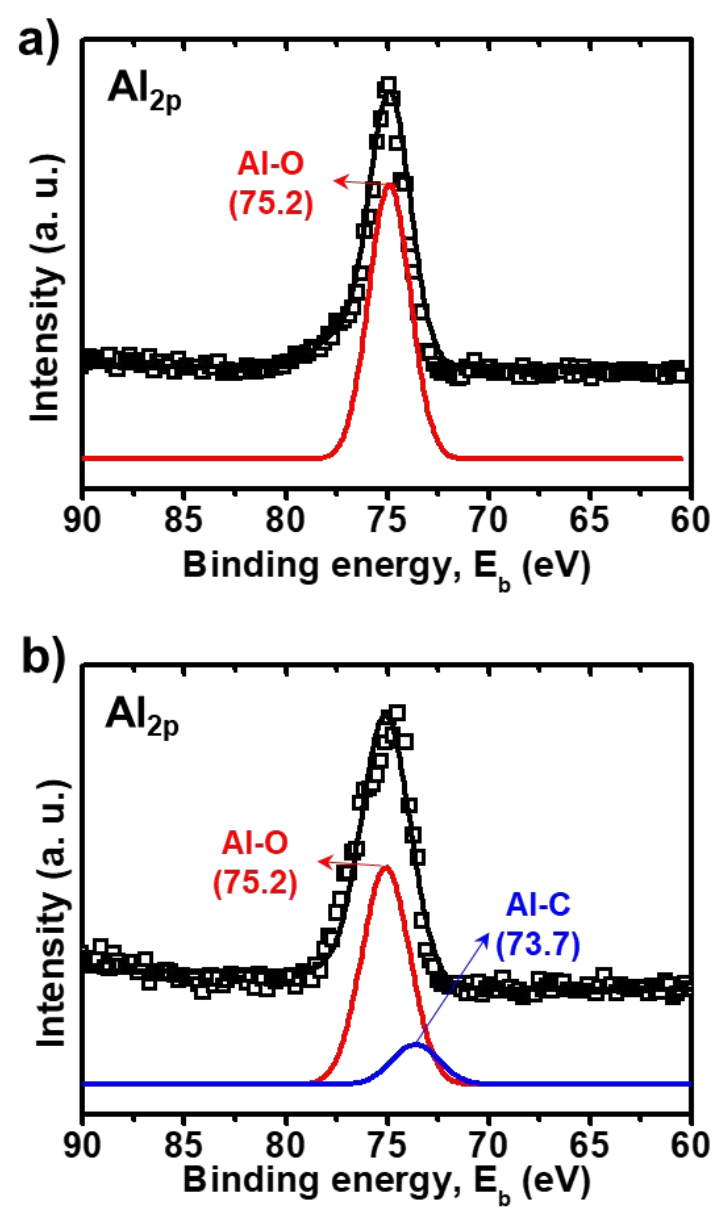

Figure S6. $\mathrm{Al}_{2 \mathrm{P}} \mathrm{X}$-ray photoelectron spectroscopy of the interface TPN film and $\mathrm{Al}_{2} \mathrm{O}_{3} / \mathrm{PI}$ substrate (a) without UV/Ozone exposure and (b) with UV/Ozone exposure to the crosslinked TPN film. 


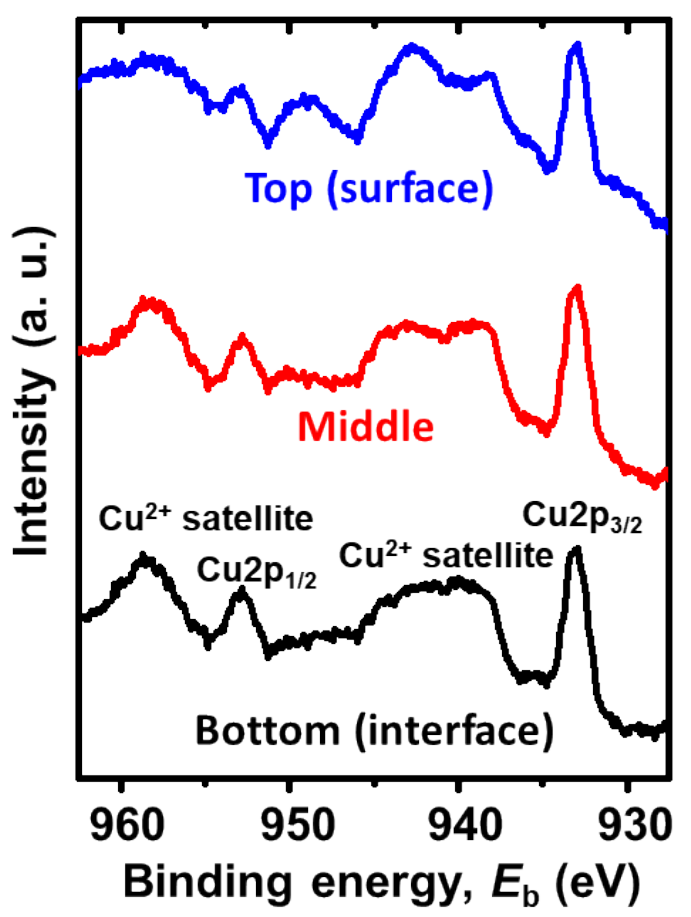

Figure S7. Depth profile XPS of $\mathrm{Cu} 2 \mathrm{p}$ for the embedded $\mathrm{Cu}^{2+}$ ions into TPN film. 


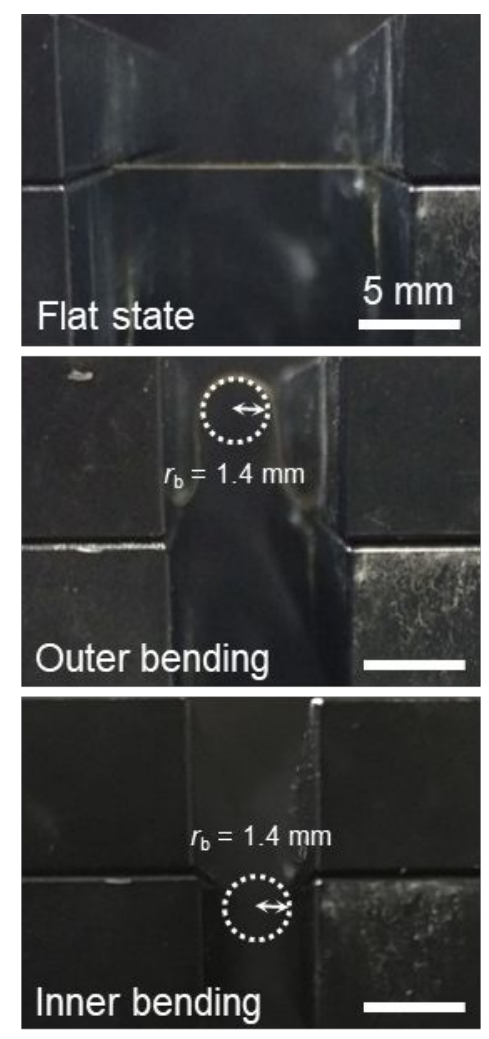

Figure S8. Bending test of graphene $/ \mathrm{Al}_{2} \mathrm{O}_{3} / \mathrm{PI}$ substrate; (top) flat, (middle) outer bending (bottom), inner bending. 

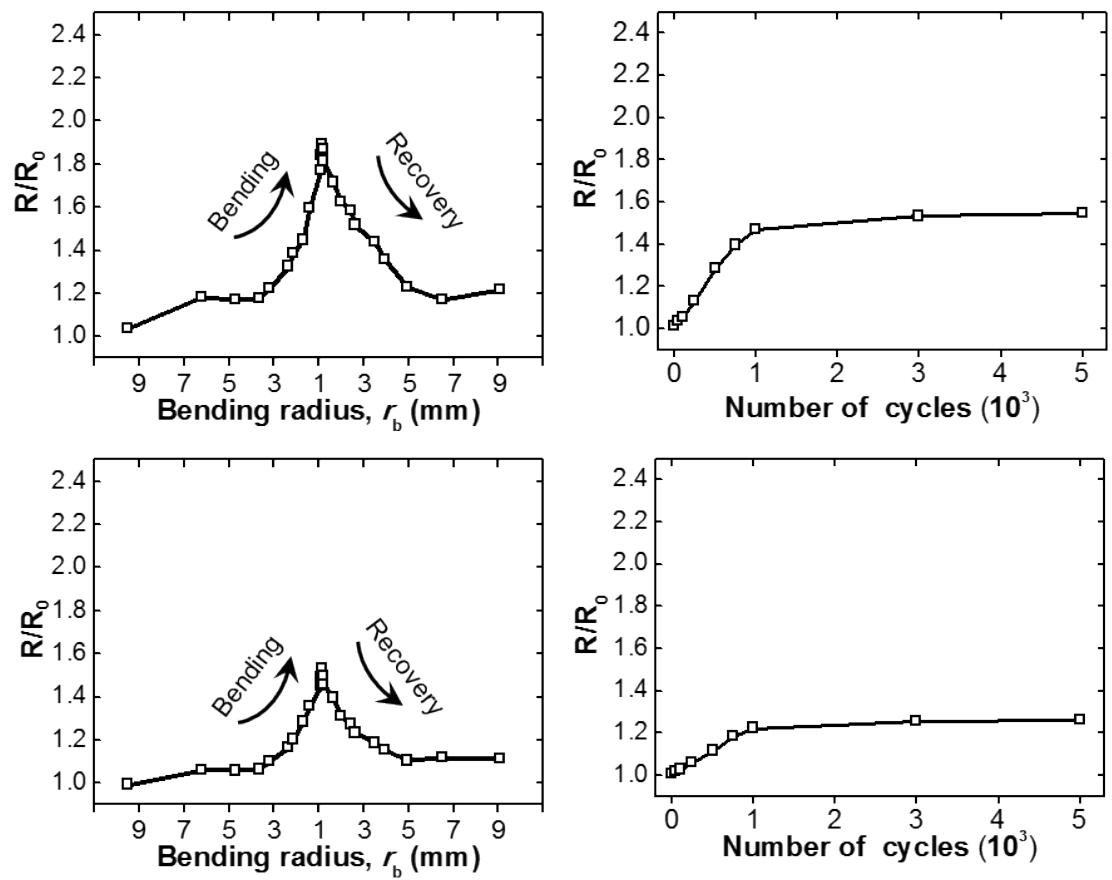

Figure S9. (a) Resistance changes of the transferred four-layer graphene with varying bending radius by outer bending test, and (b) repeated cycle test: resistance change ratio of the transferred four-layer graphene on $\mathrm{Al}_{2} \mathrm{O}_{3} / \mathrm{PI}$ substrate at bending radius $1 \mathrm{R}$; (c) inner bending test, and (d) repeated cycle test on $\mathrm{Al}_{2} \mathrm{O}_{3} / \mathrm{PI}$ substrate. 


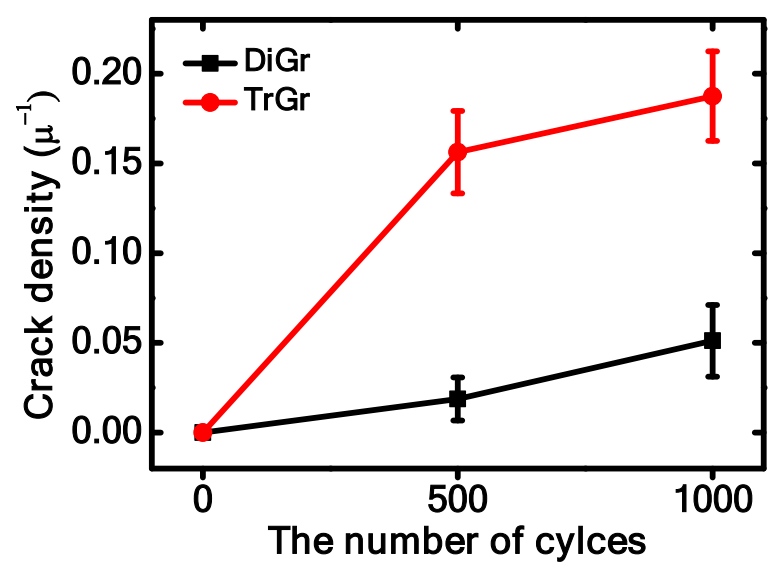

Figure S10. Crack density of DiGr (black) and TrGr (red) with varying the bending cycles. 

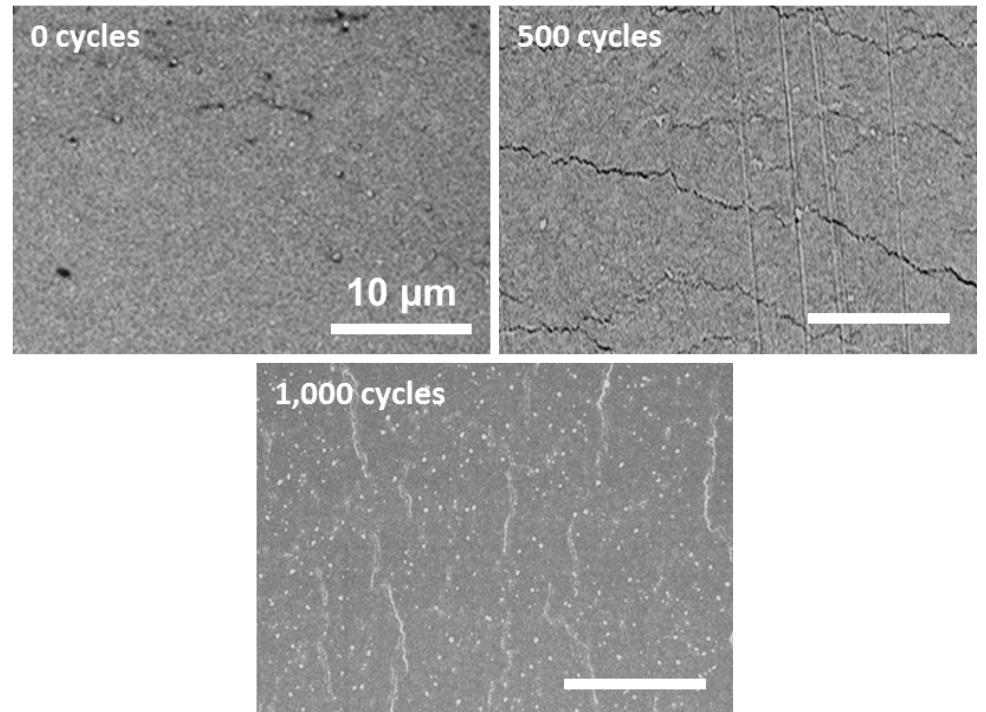

Figure S11. SEM images of bare $\mathrm{Al}_{2} \mathrm{O}_{3} / \mathrm{PI}$ substrate with different bending cycles. 